\title{
THE NEW CAMERINO UNIVERSITY RESEARCH CENTER: DESIGN OF THE BASE-ISOLATED BUINDING AND DYNAMIC TESTING
}

\author{
A. Dall'Asta ${ }^{1}$, G. Leoni ${ }^{1}$, F. Micozzi ${ }^{1}$, L. Gioiella ${ }^{1}$ N. Ceccolini ${ }^{1}$ and L. Ragni ${ }^{2}$ \\ ${ }^{1}$ SAAD, University of Camerino \\ Viale della Rimembranza 3, 63100 Ascoli Piceno (AP), Italy \\ \{andrea.dallasta, graziano.leoni, fabio.micozzi, laura.gioiella, nicola.ceccolini\}@unicam.it \\ ${ }^{2}$ Department of Civil and Building Engineering and Architecture, \\ Università Politecnica delle Marche \\ Via Brecce Bianche Ancona, Italy \\ laura.ragni@univpm.it
}

\begin{abstract}
This paper deals with the new Research Centre designed for the University of Camerino and entirely financed by the national Civil Protection Department (DPC), following the seismic events in Central Italy in 2016. The building consists of a base-isolated steel braced superstructure and r.c. sub-structures able to adapt to the complex morphology of the area. In particular, the first part of the paper illustrates the design choices made to achieve a high level of resilience and robustness of the building, i.e. to limit damage to structural and non-structural components and equipment under moderate and design seismic actions and to avoid disproportionate consequences in the event of extreme actions, larger than the design ones. The second part of the paper is focused on static and dynamic tests performed during the construction phase of the building. At the end of the structural system construction (including sub-structures, the isolation system composed by elastomeric bearings and flat sliders and the steel superstructure), the building has been tested by means of static and dynamic (snap-back) in-field tests up to a displacement of the isolation system of $280 \mathrm{~mm}$ and $220 \mathrm{~mm}$, respectively. Displacements have been imposed by means of a properly designed testing mechanism and different measure instruments have been placed in the building to register the structural response.
\end{abstract}

Keywords: Hybrid base-isolation system; elastomeric bearings; seismic reliability; seismic robustness; in-field tests; in-field snap-back tests. 


\section{INTRODUCTION}

The new Research Centre of the University of Camerino, called Chemistry Interdisciplinary Project $(C H I P)$, is a strategic building intended for high-risk activities of the chemistry and physics laboratories, whose construction started after the 2016 seismic sequences in the Central Italy [1]. The building has been entirely financed by the national Civil Protection Department $(D P C)$ and it will be also used as coordination center for civil protection post-earthquake activities in the case of possible future seismic events. Due to its use destinations, the building has been conceived by adopting a structural solution able to guarantee a high level of safety, especially with regard to seismic actions, and, at the same time, the speed of execution (and possible dismantling). To this purpose a base-isolated steel braced structure with pinned joints has been conceived with r.c. sub-structures able to adapt to the complex morphology of the area. In particular, a hybrid isolation system has been adopted, comprising High Damping Rubber Bearings $(H D R B s)$ and low-friction Flat Sliding Bearings ( $F S B S$ ) able to provide a high period of isolation and a moderate damping [2]. This solution is suitable in providing both resilience and robustness to the building. In fact, the hazard of the site does not lead to excessive displacements for strong earthquakes, which can be faced with a moderate damping. Moreover, for lower displacements the stiffness and damping of this kind of bearings only slightly increase, resulting in low accelerations of the super-structures and thus no damage (and downtime) of non-structural elements and interior contents. In addition, two complementary strategies have been adopted to also ensure adequate structural robustness against extreme actions, larger than the design ones. The first consists of a safety margin adopted for the displacement capacity of both the devices composing the isolation system and the seismic gaps on the upstream side of the building. For both of them a capacity limit greater than the maximum design displacement at the Collapse Limit State (CLS, characterized by a return period of $R_{P}=950$ years) has been required to avoid anomalous behaviours, such as the exit of the sliders out of the sliding surface or the impact of the building with neighbouring structures. The second strategy consists of adopting a steel super-structure equipped with elasto-plastic braces characterized by a proper over-strength, which is important in the case of extreme horizontal actions causing an increase in the stiffness of the $H D R$ bearings (due to their hardening behaviour for large shear strains) or the closure of the gaps. Moreover, the robustness under exceptional scenario (such as fire events or explosions) leading to the loss of vertical bearing of isolators is ensured by adopting safety supports around the devices. Finally, with the aim of increasing also the reliability of the building, an in-field experimental campaign has been planned during the design phase of the building. Many similar tests have been carried out in the past on isolated structure in Italy $[3][4][5][6]$. Some of them adopted a releasing device based on a quadrilateral articulated strut structure with a central fuse [7][8][9], as also used in this work.

In this paper a description of the building is first presented, successively the main design aspects of the base isolation hybrid system and of the in-field tests (testing device as well as reaction structure for the contrast) are illustrated in detail. The last part of the paper describes the static and dynamic in-field tests carried out at the end of the structural system construction (including sub-structures, the isolation system and the steel super-structure). Preliminary results are illustrated even in the light of tests carried out during the bearings production. For the interested reader a video description of the video can be found in [10].

\section{BUILDING DESCRIPTION AND DESIGN}

The upper part of the building (super-structure) is made of steel elements and it is developed by assuming a $7.2 \mathrm{~m} \times 7.2 \mathrm{~m}$ modular system, for a total of 7 modules along each direction, plus a cantilever zone, which spans $1.9 \mathrm{~m}$, along the entire perimeter of the building (Figure 1). 
The steel elements have been optimized in terms of dimensions and connection systems based on the single module, resulting in a significant saving on materials and an important reduction in construction time. The isolation system has been placed at the horizontal level above the r.c. elements of the sub-structure; this latter has been designed to adapt itself to the ground profile characterized by a remarkable slope. The characteristics of the soil and the variability of the thickness of the deformable layer led to the adoption of deep foundations (Figure 1).
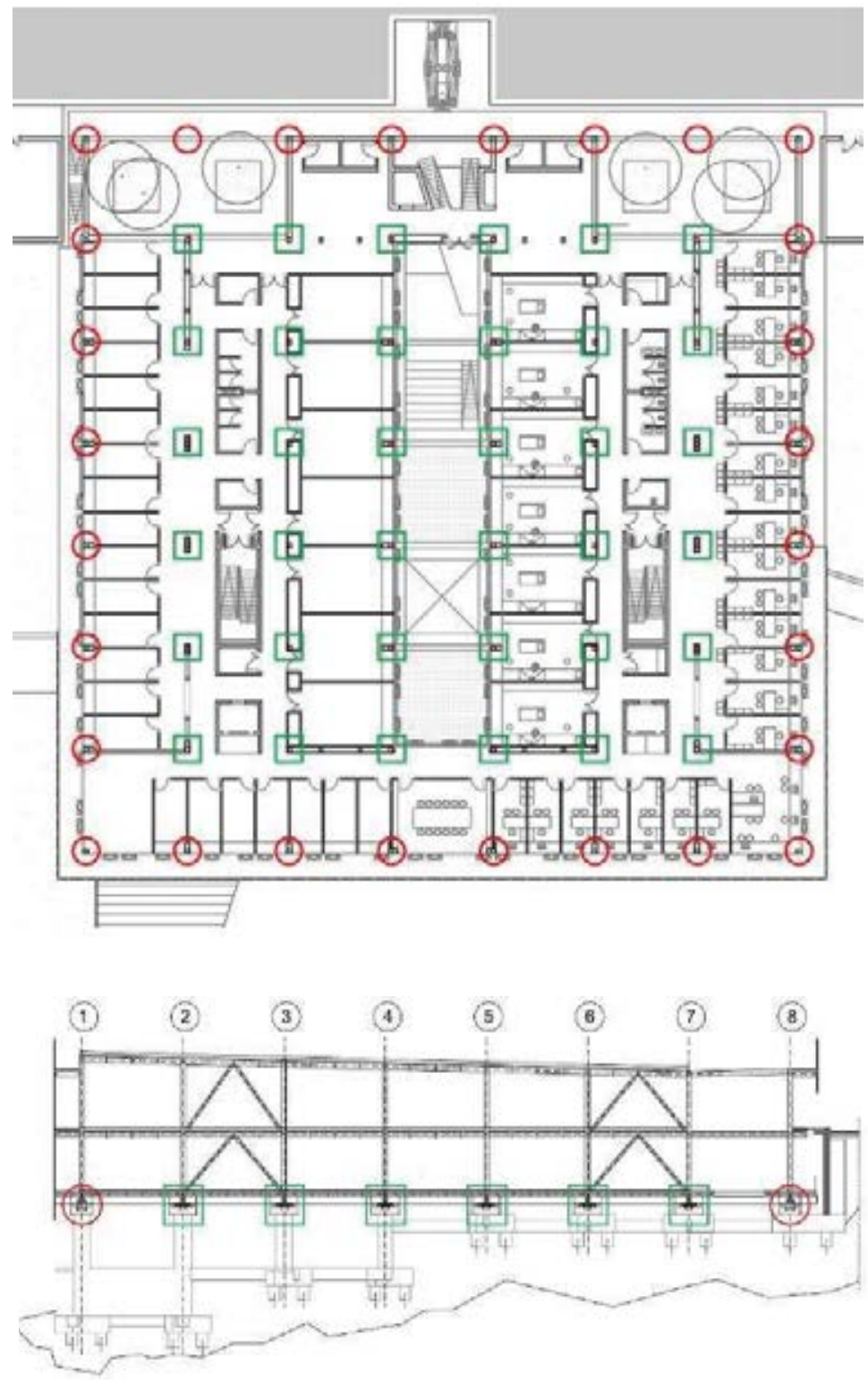

Figure 1: Plan view and longitudinal section of the building (red circles represent $H D R B S$ and green squares represent $F S B S$ ).

\subsection{Design of the base-isolated building}

The isolation system has been designed considering a target period of $\mathrm{T}_{\mathrm{is}}=3.5 \mathrm{~s}$ at the design intensity earthquake (having an exceedance probability of $2.5 \%$ in 50 years), to be able to guarantee a significant reduction of the actions transferred to the super-structure in the case of a seismic event. The solution adopted to achieve the desired period involves the use of a hybrid isolation system with $H D R B S$ arranged on the perimeter, in order to maximize torsional stiffness, 
and FSBS in the central part to support higher vertical loads. HDRBs commonly used in Italy have a damping ratio ranging from $10 \%$ to $15 \%$ [11]. However, for the design of the isolation system, the lower limit of $10 \%$ of damping and a shear stiffness equal to $0.4 \mathrm{MPa}$ (soft rubber) were assumed in the design phase, in order to deal with different producers. For what concerns the $F S B S$, a dynamic friction coefficient less than $1 \%$ was required, to reduce the activation force and possible activation of superior modes and consequently higher accelerations [2]. In a preliminary phase, the bearings were dimensioned by assuming rigid both the super-structure and the sub-structures to obtain a 1-DOF (single degree of freedom system) and by neglecting the slider friction. Thus, the elastic response spectra have been used, reduced for all the periods in the range $\mathrm{T} \geq 0.8 \mathrm{~T}_{\text {is }}$ by the equivalent damping of the HDRBs. Figure 2 shows the elastic displacement and pseudo-acceleration spectra for the considered site (Camerino, soil type B) at the different limit states, that is the Operational Limit State $(O L S)$, the Damage Limit State $(D L S)$, the Ultimate Limit State $(U L S)$ and the Collapse Limit State $(C L S)$, characterized by return periods respectively equal to $R_{P}=60$ years, $R_{P}=100$ years, $R_{P}=950$ years and $R_{P}=1950$ years, according to the national seismic code NTC 2018 [12] for the use class IV. The design was carried out by deriving the maximum displacement of the isolators from the displacement spectrum at the $C L S$ corresponding to the isolation period of $3.5 \mathrm{~s}$, which is about $0.27 \mathrm{~m}$. An average design shear strain equal to 1.5 is assumed, ensuring a significant safety margin against possible shear failure, even in the presence of accidental torsional effects, because significantly lower than the maximum value allowed by the European standard on antiseismic devices EN15129 [13], which establishes a value equal to 2.5.
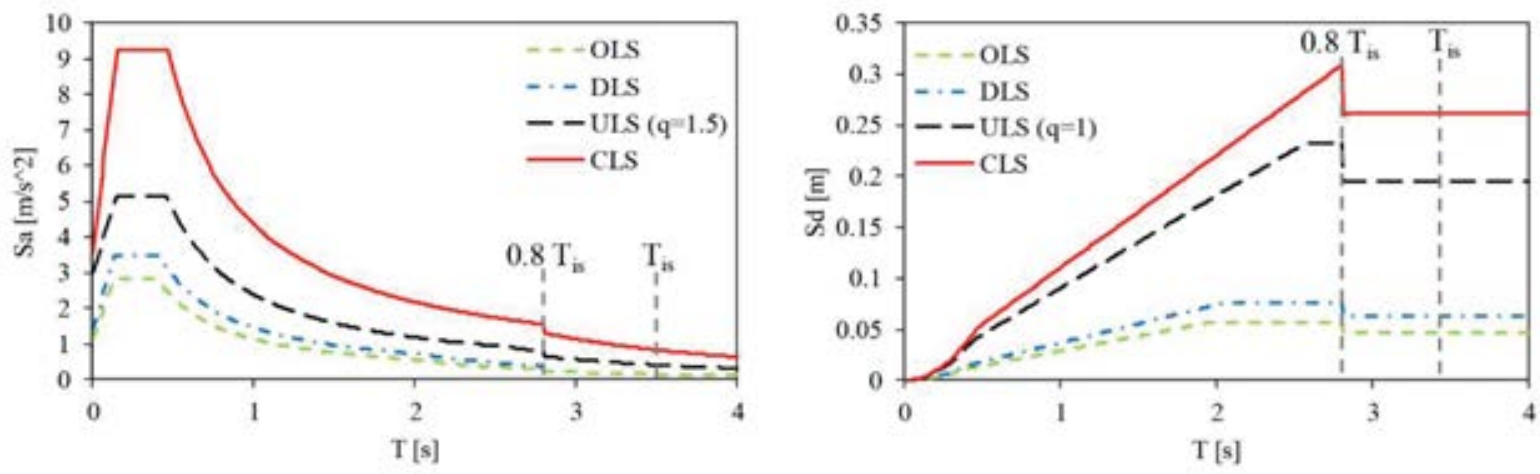

Figure 2: Elastic pseudo-acceleration and displacement spectra at the different limit states

Based on the total rubber area obtained and on the devices generally available on the national market, the following types of devices have been chosen: $(i)$ elastomeric isolators with a diameter of $600 \mathrm{~mm}$, total height of rubber $184 \mathrm{~mm}$, with horizontal rigidity $0.62 \mathrm{kN} / \mathrm{mm}$ and maximum displacement $350 \mathrm{~mm}$, (ii) sliding supports with a maximum displacement of $400 \mathrm{~mm}$ and friction coefficient lower than $1 \%$. The final choice of devices led to a slightly higher isolation period equal to $\mathrm{T}_{\text {is }}=3.60 \mathrm{~s}$. It should be noted that the displacement capacity of both the devices is larger than the maximum displacement at the $C L S$ accounting also for torsional effects, which can be estimated as $270 \cdot 1.2=324 \mathrm{~mm}$. As already highlighted in the introduction, larger safety assumption guarantees the absence of anomalous behaviours due, for example, to the exit of the sliders for actions greater than those considered in the design. The higher value chosen for the FSBS with respect to the $H D R B S$ is related to the lower robustness of the former because displacements higher than the sliding surface dimension suddenly lead to a loss of bearing capacity. On the contrary, rubber isolators can usually sustain displacements larger than their nominal capacity without a significant loss of performance. An adequate dimension (350 
$\mathrm{mm}$ ) has also been assumed for the seismic gaps placed in the upstream part of the building at the road level and proper precautions have been taken with regard to plants and installations, which must absorb the entire design displacement without damage or loss of functionality. After the isolation system had been design, the seismic analyses of the building were carried out by modelling all the structural system components (the super-structure, the sub-structure and the isolation system) as linear elastic elements, having satisfied the conditions reported in [12] for the linear modelling of isolation systems. More details about analysis results and safety checks (stiffness and resistance verifications at the DLS and ULS of the super-structure and detailed verification at the CLS of the isolation devices) can be found in [1].

\subsection{Design of the releasing device}

During the building construction, in-field dynamic "snap-back" test and static tests have been performed in order to verify the actual behaviour and the characteristic of the isolation system. With this purpose, the design of the releasing device and relevant contrasting structures has been conducted during the design phase of the building. In particular, a "reaction box" made by r.c. walls and founded on piles has been arranged in the upstream part of the building to place the releasing device, as depicted in Figure 1. Figure 3 reports a plan view and a longitudinal cross section of the "reaction box" and of the releasing device. It is worth to note that the estimated maximum reaction force is about $5000 \mathrm{kN}$ and all the nine piles of the box base slab collaborate in contrasting it. Moreover, the reinforcements of the building slab, where the releasing device is attached, has been properly designed and detailed according to a strut-and-tie tall beam model (Figure 4 and Figure 5 a). Similarly, proper steel reinforcement bars have been located in the r.c. walls, especially near the location of the hydraulic jacks in order to avoid local punching shear mechanism (Figure $5 \mathrm{~b}$ ).

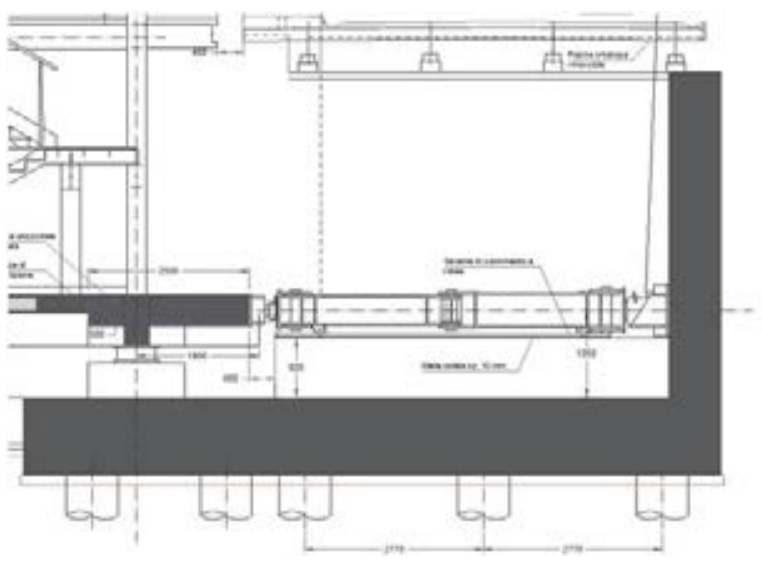

(a)

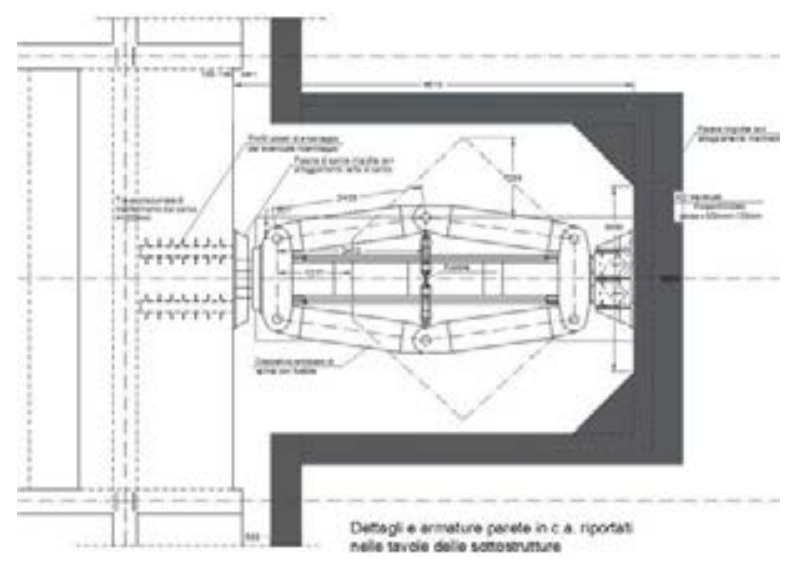

(b)

Figure 3: Lateral (a) and plan (b) view of the testing device and its "reaction box"

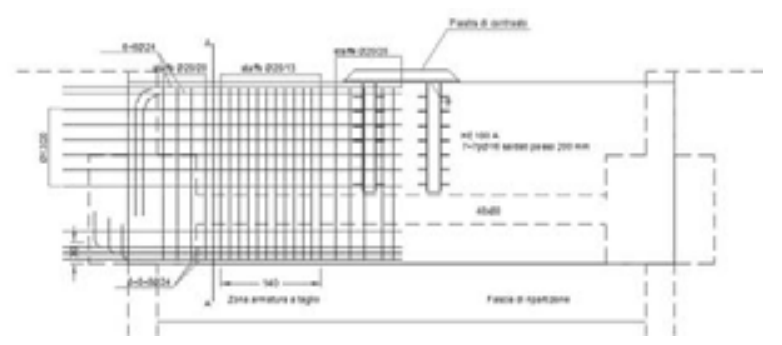

(a)

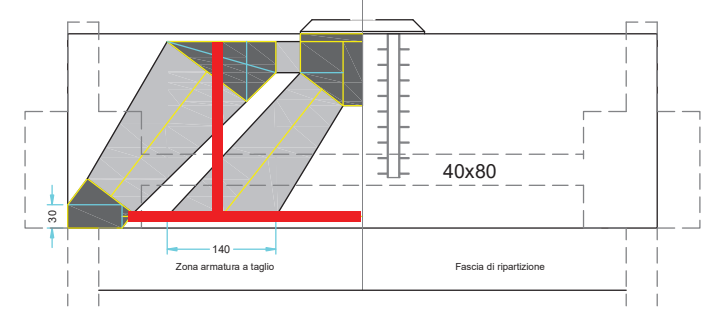

(b) 
Figure 4: Reinforcement details of the tall beam on the building side (a) and strut-and-tie main mechanism (strut=grey zones, tie=red solid lines, nodes $=$ dark grey zones) (b).

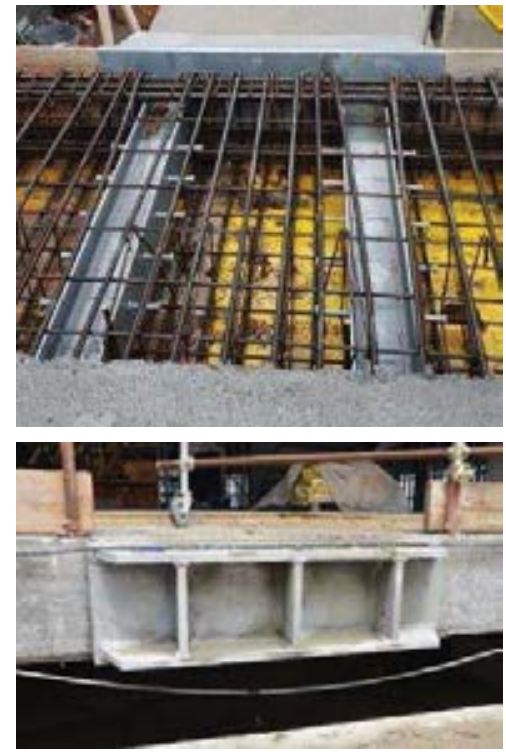

(a)

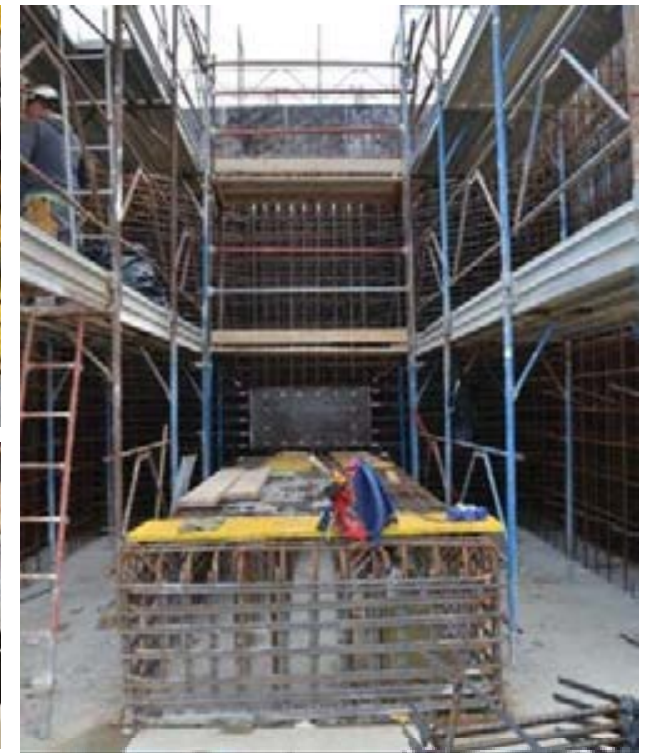

(b)

Figure 5: Reinforcement details of the building tall beam (a) and the reaction walls (b).

The tests are carried out using two hydraulic jacks (a maximum force of $5000 \mathrm{kN}$ each and a maximum stroke of $300 \mathrm{~mm}$ ) in series with the releasing device and two load cells on the opposite side (Figure 6 a). This latter is conceptually a quadrilateral articulated steel strut blocked by the central tie and supported by steel wheels on rails to ensure the longitudinal displacement with the lowest friction force. A fuse element made of high strength turned rod (Figure $6 \mathrm{~b}$ ) is lodged in the middle of the tie element. The strut angle respect to the pushing direction defines the ratio between the pushing force and the tension force applied to the tie. The turning geometry and the low plastic deformation of high strength steel used for the fuse ensure a brittle rupture of the rod and a high accuracy of the release force. A friction dissipative device (Figure $6 \mathrm{c}$ ), similar to the ones used for falling rock protection barrier, have been installed in parallel with the tie element.

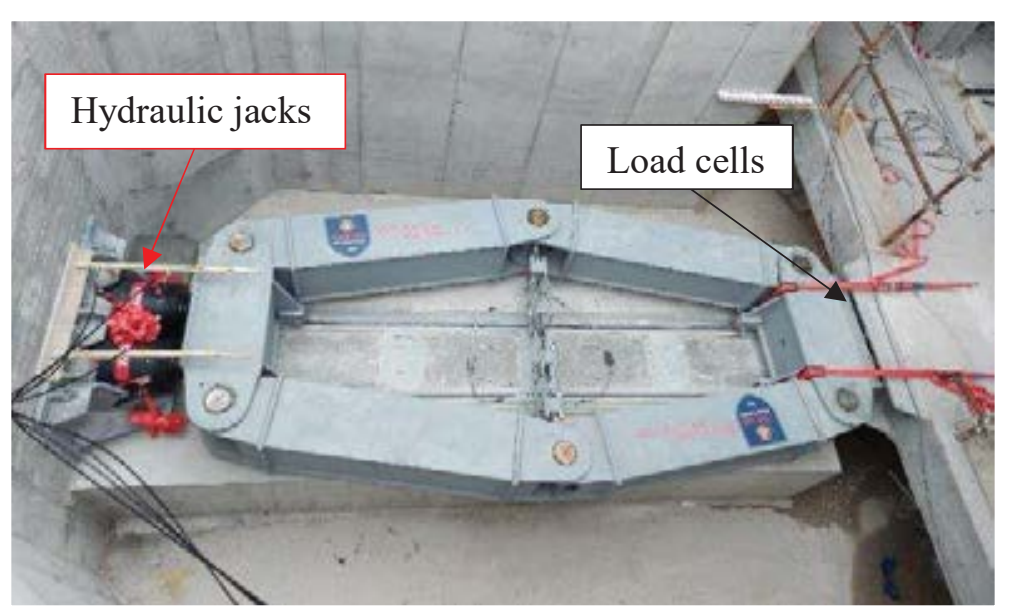

(a)

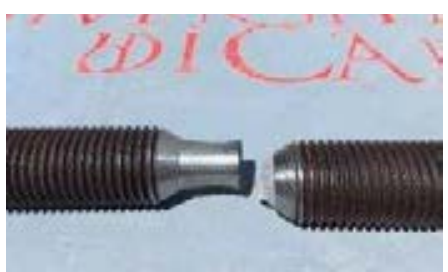

(b)

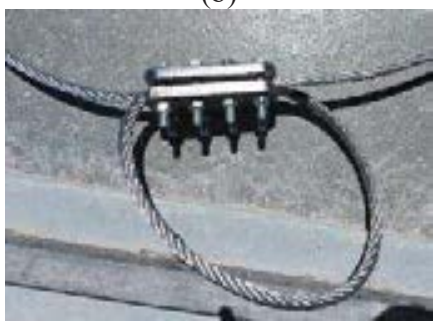

(c)

Figure 6: Releasing device equipped with hydraulic jacks and load cells (a) and high strength turned rod fuse after the rupture (b), after the rupture and friction dissipative device (c). 
After the fuse rupture, the elastic energy stored in the device is partially dissipated by the friction dissipative device (Figure $6 \mathrm{c}$ ), avoiding damages to both the cylindrical articulations and the strut elements. The dissipating mechanism is based on a friction clamp applying a calibrated force (controlled by belleville washers) to the looped cable [14]. The loop ensures an end-stroke of the rope sliding. Finally, to further secure the cell loads from possible impacts during the release phase, the releasing device was anchored on the building side using ratchet belts. It is worth to note that both the device mass and the device friction force are negligible with respect to the building mass and response.

\section{STATIC AND DYNAMIC IN-FIELD TESTS}

The isolation system of the CHIP building has been tested during the construction phase, when the structures were completed and no partition, nor external walls, neither equipment were installed. In particular, a series of Dynamic Snap-Back $(D S B)$ tests and Quasi Static $(Q S)$ tests have been performed, during two different days $\left(3^{\text {rd }}\right.$ and $6^{\text {th }}$ July 2020$)$. The equipment used to move the building during the $Q S$ tests and the first part of the DSB tests has been described in section 2.2, while some measurement instrumentations are illustrated in Figure 7.

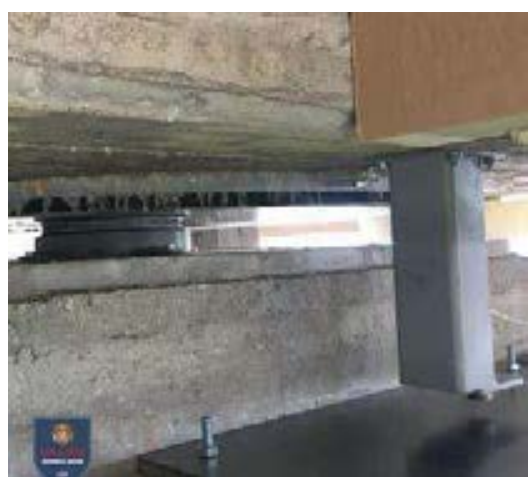

(a)

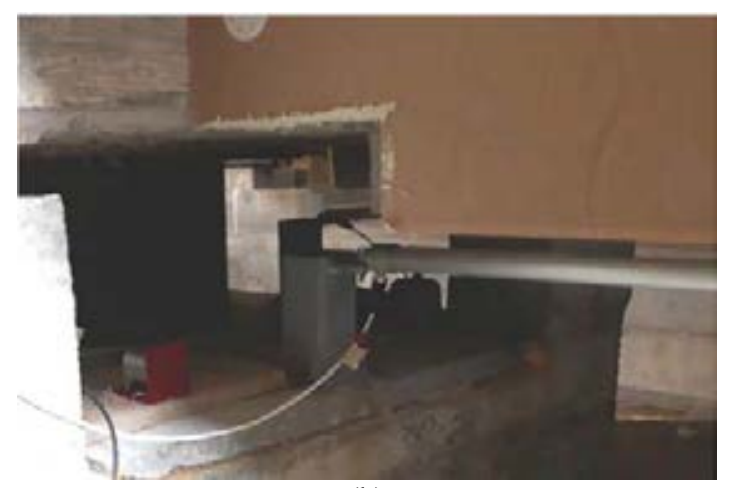

(b)

Figure 7: Sensors for recording vertical (a) and horizontal (b) displacements.

The sequence of the tests, the maximum applied displacements and thrust forces are reported in Table 1. Residual displacements at long time (immediately before the subsequent test) are also reported in the last column of the table. The last test (QS7), in which the maximum displacement has been imposed, showed the largest residual drift $(31.4 \mathrm{~mm})$ but a large part of it was recovered after few days from the test (final residual displacement equal to $25 \mathrm{~mm}$ ).

\begin{tabular}{|c|c|c|c|c|}
\hline Test & Date & $\begin{array}{c}\text { max displacement } \\
{[\mathrm{mm}]}\end{array}$ & $\begin{array}{c}\max \text { Force } \\
{[\mathrm{kN}]}\end{array}$ & $\begin{array}{c}\text { Residual displacement } \\
{[\mathrm{mm}]}\end{array}$ \\
\hline Pre-test1 & $3^{\text {rd }}$ July & 0.0 & 518 & 0.0 \\
\hline$D S B 2$ & $3^{\text {rd }}$ July & 177.3 & 2729 & 15.2 \\
\hline QS3 & $3^{\text {rd }}$ July & 232.4 & 3206 & 22.1 \\
\hline$D S B 4$ & $6^{\text {th }}$ July & 109.4 & 1756 & 22.1 \\
\hline$D S B 5$ & $6^{\text {th }}$ July & 226.9 & 3122 & 22.0 \\
\hline$D S B 6$ & $6^{\text {th }}$ July & 121.8 & 1786 & 22.4 \\
\hline QS7 & $6^{\text {th }}$ July & 284.6 & 3834 & $31.4 \longrightarrow 25$ \\
\hline
\end{tabular}

Table 1: Tests sequence

Figure 8 (a) reports results in terms of response curves, i.e. loading force-displacement curves of some $D S B S$ and the loading and unloading force-displacement curves of the two $Q S$ 
tests, showing some characteristic behaviours of hybrid isolation systems composed by HDRBS and FSBs. The first one is the breakaway friction force of the system. During DSB2 test the structure is moved for the first time from its initial position and starts to move after reaching a force of $700 \mathrm{kN}$, which is higher than the breakaway friction force observed during all the subsequent tests. The reason is that the trajectory followed by all the tests is almost the same, thus the lubrification of the sliding surfaces increases at each test. Furthermore, from the unlading branch, the dynamic friction force can be estimated since the vertical drop at the maximum force is theoretically 2 times this force. The obtained values, highlighted in Figure 8 (a), are approximately equal to $400 \mathrm{kN}$ for both the $Q S$ tests, thus the dynamic friction force is estimated to be nearly $200 \mathrm{kN}$, which is significantly lower than static friction force. Both the reduction of the friction due to repeated cycles and the difference between static and dynamic friction are phenomena already known in specific technical literature [15]. However, it can be noted that after the tests the building does not restore its initial position, thus the initial force measured to start the movement is not only related to the friction of FSBs but also to the residual force of $H D R B s$. From Figure 8 (a) it is clear that after having performed the DSB2 test, the succeeding $Q S 3$ test starts in a displaced configuration equal to $15 \mathrm{~mm}$ and equal to $23 \mathrm{~mm}$ for all the following tests, resulting in a horizontal shifting of the responses.

Another characteristic aspect that can be observed from the tests deals with the viscous behaviour of $H D R B S$ (i.e. the influence of the displacement rate on the response). To better explain this point the response curves of Figure 8 (a), once deducted the dynamic friction force previously estimated and scaled with respect to a single $H D R B$, have been compared in Figure 8 (b) with the response curves of two type tests, carried out according to [13] before the bearings production. Specifically, such tests are the Horizontal Cyclic test at $150 \%$ shear deformation at third cycle ( $H C$ in Figure 8 b) and One Side Ramp test (OSR in Figure 8 b). It can be observed that the $H C$ test (performed at $0.5 \mathrm{~Hz}$, with a mean speed of $550 \mathrm{~mm} / \mathrm{s}$ ) is stiffer and more dissipative than all the other tests, which have been carried out with a significantly lower displacement rate (about $5 \mathrm{~mm} / \mathrm{s}$ the $O S R$ type test and $0.2 \mathrm{~mm} / \mathrm{s}$ the load branch of in-field $Q S$ tests). A further remark involves the in-field $Q S$ tests, whose loading branch is very close to the OSR test, even though the speed is different. On the contrary, the unloading branches are significantly different due to the different unloading modalities, resulting in a lower energy dissipation and a higher recentring capacity of the $Q S$ in-field tests. For what concerns the loading phase of the $D S B 2$ in-field test, the response significantly differs from the other tests because it is affected by the first breakaway friction force and by the first cycle effect of the "virgin" rubber, i.e. the first time that all the $H D R B S$ reach this level of strain [16][17].

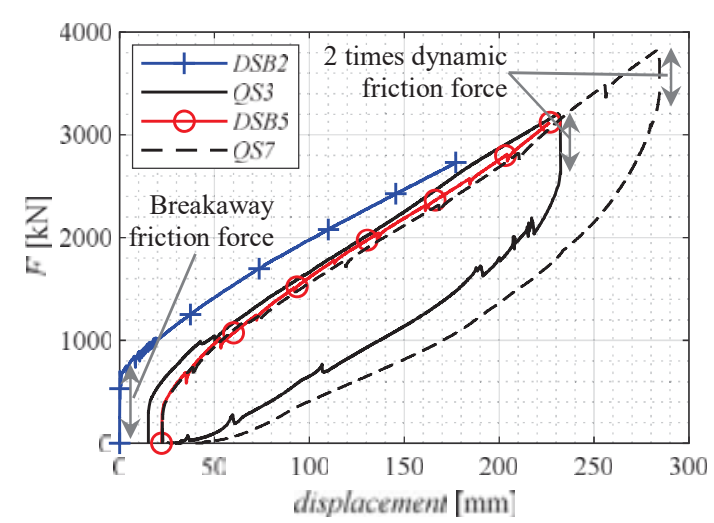

(a)

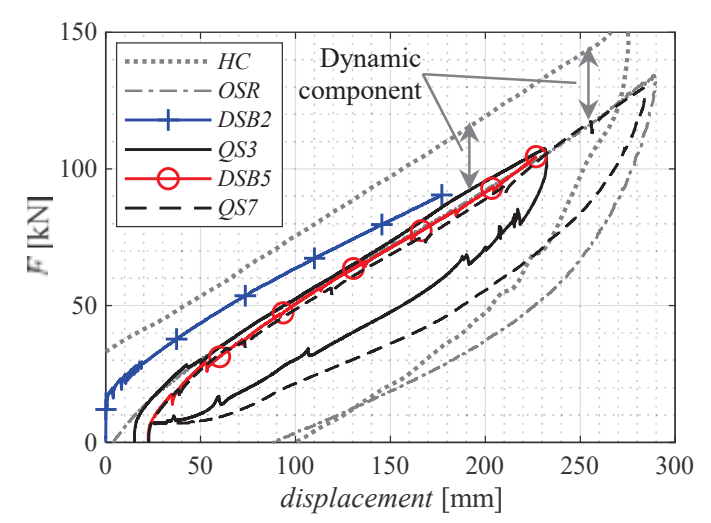

(b)

Figure 8: Force-displacement curves of the in-field tests (a) and their comparison with type tests with reference to a single $H D R B(\mathrm{~b})$. 
Finally, Figure 9 summarizes the displacement time-histories observed during the DSB tests. It is worth to note that the isolation period, ranging between $2.5 \mathrm{~s}$ and $3.12 \mathrm{~s}$, is lower than the design period due to the lower mass of the isolated building during the tests with respect to the design one. Furthermore, it can be observed that the free vibration of the building oscillates between a non-zero displacement configuration, but a slow recentring displacement can be recognized by looking at the response after $4 \mathrm{~s}$ from the release. This confirms the importance of the viscous component of $H D R B S$ response, which leads to a final residual displacement of around 22-25 $\mathrm{mm}$ (see Table 1).

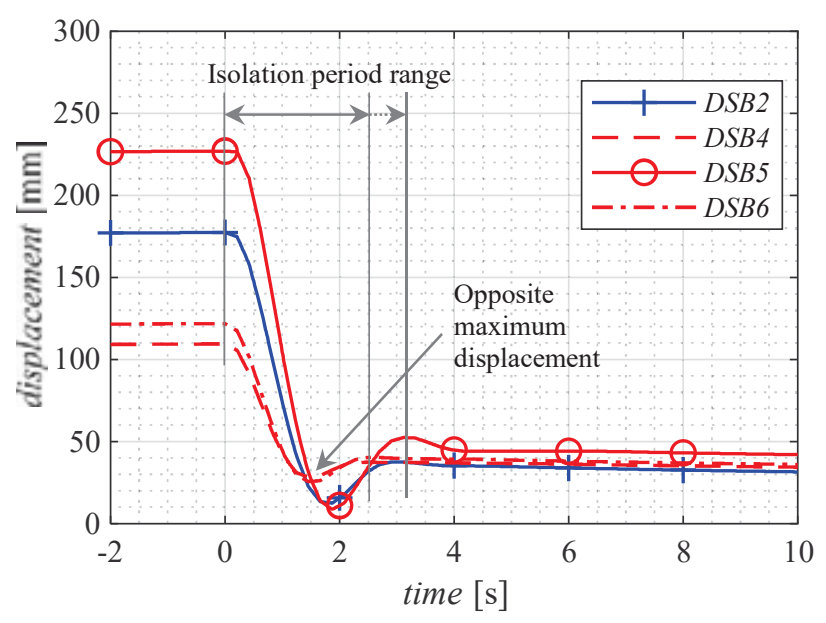

Figure 9: Displacements time-histories of in-field $D S B$ tests.

\section{CONCLUSIONS}

This paper describes the isolated-building of the new Research Centre of the Camerino University, called CHIP (Chemistry Interdisciplinary Project), with particular focus on dynamic and static in-field tests carried out during the building construction to characterize the isolation system response. The design of the in-field experiment campaign has been developed in parallel with the design of the building. In particular, a quadrilateral articulated steel strut element has been designed and used as releasing device, furthermore a reaction box has been designed close to the building and properly dimensioned. A pair of hydraulic jacks, whose force has been monitored through load cells, has been used for the pushing phase, while the displacements of the isolation system has been recorded thanks to horizontal and vertical transducers. Preliminary results, in terms of force-displacement response curves of quasi-static tests and displacement time-histories of dynamic snap-back tests have been showed and discussed. By analysing the force-displacement response curves of the quasi-static tests, both the static and dynamic friction force of FSBS has been estimated. The response of HDRBs has been also identified and compared with type tests carried on single bearing devices. Finally, the displacement time-histories of the snap-back tests have been analysed by estimating the isolation period range and the recentring capacity of the isolation system.

\section{REFERENCES}

[1] A. Dall'Asta, G. Leoni, F. Micozzi, L. Gioiella and L. Ragni, A Resilience and Robustness Oriented Design of Base-Isolated Structures: The New Camerino University Research Center. Front. Built Environ. 6:50. 2020. doi: 10.3389/fbuil.2020.00050 
[2] Ragni L, Micozzi F, Tubaldi E and Dall'Asta A. Seismic behaviour of a rc frame isolated by hdnr bearings under increasing intensity levels. 7th ECCOMAS Thematic Conference COMPDYN 2019. Crete, Greece, 24-26 June 2019

[3] F. Bettinali, M. Forni, M. Indirli, A. Martelli, P. Masoni, G. Bonacina, On site dynamic tests ofa large seismically isolated building. Proceedings of International Meeting on Earthquake Protection of Buildings, Ancona, Italy. 1991, p. 145.

[4] M. Forni, A. Martelli, B. Spadoni, E. Casalini, G. Bonacina, G. Pucci, Dynamic tests on seismically isolated structure mockups and validation of numerical models. Proceedings of International Meeting on Earthquake Protection of Buildings, Ancona, Italy. 1991, p. 169.

[5] A.R. Bixio, M. Dolce, D. Nigro, F.C. Ponzo, F. Braga, M. Nicoletti, Repeatable dynamic re-lease tests on a base-isolated building. Journal of Earthquake Engineering 2001;5(3):369-93.

[6] F. Braga, M. Laterza. Field testing of low-rise base isolated building. Engineering Structures, 2004; 26(11): 1599-1610. DOI: 10.1016/j.engstruct.2004.06.002.

[7] N.D. Oliveto, G. Scalia G, G. Oliveto. Time domain identification of hybrid base isolation systems using free vibration tests. Earthquake Engineering \& Structural Dynamics 2010: DOI: 10.1002 /eqe.984.

[8] F.C. Ponzo, R. Ditommaso, D. Nigro, R. Romaniello, D. Cardone, Analysis of dynamic behaviour of a base isolated building: a release test in Augusta (SI), 2nd European conference on earthquake engineering and seismology, Instanbul, 2014

[9] M.F. Ferrotto, L. Cavaleri, F.Di Trapani, P. Castaldo. Full scale tests of the base-isolation system for an emergency hospital, 7th ECCOMAS Thematic Conference COMPDYN 2019. Crete, Greece.

[10] Web site URL: https://youtu.be/Ou95s6_Jcws

[11] FIP, S02-Isolatori Elastomerici Serie SI (italian), 2016. Available online at: www.fipindustriale.it (October, 2019).

[12] NTC 2018 (2018). Aggiornamento delle "Norme Tecniche per le costruzioni" (in italian). D:M: 17/01/2018 Ministry of Infrastructure and Transport.

[13] European Committee for Standardization. EN 15129:2010 - Antiseismic devices, Brussels, Belgium, 2010.

[14] L. Castanon-Jano, E. Blanco-Fernandez, D. Castro-Fresno, F. Ballester-Muñoz, Energy Dissipating Devices in Falling Rock Protection Barriers. Rock Mechanics and Rock Engineering 2017; 50(3): 603-619. DOI: 10.1007/s00603-016-1130-x.

[15] M. Dolce, D. Cardone, F. Croatto, Frictional Behavior of Steel-PTFE Interfaces for Seismic Isolation. Bulletin of Earthquake Engineering, 3:75-99, 2005

[16] E. Tubaldi, L. Ragni, A. Dall'Asta, H. Ahmadi, A. Muhr, Stress softening behaviour of HDNR bearings: modelling and influence on the seismic response of isolated structures. Earthquake Engineering \& Structural Dynamics, 2017. DOI: 10.1002/eqe.2897.

[17] L. Ragni, F. Micozzi, E. Tubaldi and A. Dall'Asta (2020): Behaviour of Structures Isolated by HDNR Bearings at Design and Service Conditions, Journal of Earthquake Engineering, DOI: $10.1080 / 13632469.2020 .1776792$ 